\title{
Plasma Drug Level Validates Self-Reported Adherence but Predicts Limited Specificity for Nonadherence to Antiretroviral Therapy
}

\author{
Robert Balikuddembe, ${ }^{1}$ Joshua Kayiwa, ${ }^{2}$ David Musoke, ${ }^{3}$ Muhammad Ntale, ${ }^{4}$ \\ Steven Baveewo, ${ }^{5}$ Paul Waako, ${ }^{1}$ and Celestino Obua ${ }^{1}$ \\ ${ }^{1}$ Department of Pharmacology and Therapeutics, School of Biomedical Sciences, College of Health Sciences, Makerere University, \\ P.O. Box 7072, Kampala, Uganda \\ ${ }^{2}$ Data Department, Joint Clinical Research Centre, P.O. Box 10005, Kampala, Uganda \\ ${ }^{3}$ Department of Pharmacology and Therapeutics, Gulu University, P.O. Box 166, Gulu, Uganda \\ ${ }^{4}$ Department of Chemistry, School of Physical Sciences, College of Natural Sciences, Makerere University, \\ P.O. Box 7072, Kampala, Uganda \\ ${ }^{5}$ Clinical Epidemiology Unit, School of Medicine, College of Health Sciences, Makerere University, P.O. Box 7072, Kampala, Uganda
}

Correspondence should be addressed to Celestino Obua, cobua@chs.mak.ac.ug

Received 21 November 2011; Accepted 20 December 2011

Academic Editors: G. Hempel, D. K. Miller, and K. Wada

Copyright (C) 2012 Robert Balikuddembe et al. This is an open access article distributed under the Creative Commons Attribution License, which permits unrestricted use, distribution, and reproduction in any medium, provided the original work is properly cited.

Introduction. Adherence to antiretroviral therapy (ART) in low-income countries is mainly assessed by self-reported adherence (S-RA) without drug level determination. Nonadherence is an important factor in the emergence of resistance to ART, presenting a need for drug level determination. Objective. We set out to establish the relationship between plasma stavudine levels and S-RA and validate S-RA against the actual plasma drug concentrations. Methods. A cross-sectional investigation involving 234 patients in Uganda. Stavudine plasma levels were determined using high-performance liquid chromatography. We compared categories of plasma levels of stavudine with S-RA using multivariable logistic regression models. Results. Overall, 194/234 patients had S-RA $\geq$ 95\% (good adherence) and 166/234 had stavudine plasma concentrations $\geq 36 \mathrm{nmol} / \mathrm{L}$ (therapeuticconcentration). Patients with good S-RA were eight times more likely to have stavudine levels within therapeutic concentration (Adjusted Odds Ratio: 7.7, 95\% Confidence Interval: 3.5-7.0). However, of the 194 patients with good S-RA, 21.7\% had below therapeutic concentrations. S-RA had high sensitivity for adherence (91.6\%), but limited specificity for intrinsic poor adherence (38.2\%). Conclusions. S-RA is a good tool for assessing adherence, but has low specificity in detecting nonadherence, which has implications for emergence of resistance.

\section{Introduction}

The role of good adherence in the attainment of positive clinical outcomes among HIV-infected patients on the lifelong antiretroviral therapy (ART) has been well demonstrated in previous studies $[1,2]$. Good adherence has been associated with suppression of the virus, reduction in resistant strains of HIV, delayed progression to AIDS, and improved quality of lifeand reduction in AIDS-related mortality, among other benefits [3-14]. Globally, suboptimal or poor adherence levels to ART are associated with poor viral suppression and rebound plasma viremia, which leads to emergency of drug resistant HIV strains, increasing risk of transmission of multidrug resistant viruses within the population [15]. Studies conducted around the world have reported adherence rates ranging between $40-70 \%$ including a rate of $68 \%$ for Uganda [15-17].

Accurate assessment of patient adherence to antiretroviral medication is critical to maintain the ART benefits and reduce the risks associated with poor adherence. Among 
treatment centres within sub-Saharan Africa, adherence is assessed using various methods including patients' selfreports, announced or unannounced pill counts, use of pharmacy refill records, compliance to clinical appointments, medication diaries, linear analog scales, electronic monitoring systems, and sometimes measurement of plasma drug levels [18-20]. However, nearly all these methods are associated with known limitations [16, 21-23] and thus fail to capture the important dimensions of adherence, which is not commonly done in resource limited countries [22].

In Uganda, adherence to ART is commonly assessed using self-report adherence (S-RA). Recent literature has shown diverse views about the degree of reliability of S-RA [24]. Furthermore, limited information is available regarding the sensitivity and specificity of this adherence assessment method validated using plasma drug concentration levels. In the current study, we aimed at establishing the relationship between plasma drug levels and adherence levels determined by S-RA among HIV/AIDS patients on stavudine-containing regimen in Uganda.

\section{Methods}

2.1. Study Site and Design. This was a cross-sectional study of patients attending the ART clinic at the Joint Clinical Research Centre (JCRC) in Kampala, Uganda. The study was conducted between June 2006 and June 2007, recruited patients were aged 18 to 50 years, who had been on treatment for at least three months and were willing to give a written consent. At the JCRC clinic, patients on ART are assessed for S-RA at every visit by an adherence counselor basing on the number of pills reported to have been taken. A patient is classified to be adherent to ART if their S-RA is $95 \%$ or more. Their CD4 counts are also measured at initiation of therapy and then once every six months, as part of the routine monitoring activities. These data sets are recorded on their clinical charts and later stored in an electronic database.

\subsection{Sample Size Calculations and Inclusion Criteria. Given} the diversity in the characteristics of patients attending the JCRC clinic, we anticipated their adherence levels to be a little lower than the global adherence levels of $70 \%$, but within Uganda's adherence levels of $68 \%$ as documented in other studies [15-17]. In our power calculations, we used the formula for computing proportions of sample sizes as documented by Schaeffer et al. (1990) [25], which gives similar results to the Kish et al. (1965) formula [26]. With the assumption of a $68 \%$ adherence rate among the 750 patients on ART, on average, who attended the clinic weekly in 2006, the study would be sufficiently powered to detect a $5 \%$ effect if 232 participants would be recruited. In the end, however, this study recruited 234 patients, who were on the Triomune30 regimen for at least three months and had consistent S-RA assessments during the last three clinic encounters. Clients who had taken their last medication dose before consent or were not willing to consent for a blood draw or were taking concomitant medication which was likely to interfere with the bioavailability of stavudine such as methadone, were excluded from participating.

2.3. Data Collection. Demographic, clinical, and S-RA data were extracted from the patient records using a check list. Patients with mean S-RA of $95 \%$ and above on the past three clinic visits were classified as adherent, whereas those with mean S-RA below 95\% within the same duration were classified as nonadherent. Predose venous blood samples (4 mls) from each participant were collected in prelabeled EDTA vacutainer for plasma drug level analysis.

2.4. Laboratory Procedures. Reference stavudine and the internal standard (thymidine oxetane) were obtained from Bristol-Myers Squibb. Distilled water was obtained from Mili-Q water purification system. The analytical column was a Nova pak $\mathrm{C}_{18} 5$ micro meter particle size, $150 \times 3.9 \mathrm{~mm}$ (Waters) with a guard column Nova pak $\mathrm{C}_{18}$ (Waters). Varian solid-phase extraction cartridges (Varian, Netherlands: part no. 12102028 lot number 0715906 , code 33106 t phase C18, $3 \mathrm{cc} 500 \mathrm{mg}$ ) were used for extraction of the drugs from the plasma samples. HPLC-grade acetonitrile and methanol were purchased from BDH (U) Limited, Kampala. Blank plasma was obtained from the Uganda Blood Bank, Nakasero, Kampala.

Stavudine stock solution of $1.5 \mathrm{mg}$ was prepared in $10 \mathrm{~mL}$ methanol, with serial dilutions with distilled water, to provide solutions of $10 \mu \mathrm{g}$ to $550 \mu \mathrm{g} / \mathrm{mL}$. Calibration concentrations of $35,50,78,312,625,1250$, and $2500 \mathrm{nmol} / \mathrm{L}$ in blank plasma were used to construct the standard curve from the stock solution. A second stock solution of stavudine was used to prepare the quality control standards in plasma. All the calibration and the quality control standards were contained in polypropylene microtubes and stored at $-70^{\circ} \mathrm{C}$ until assay. Stock solution of internal standard of $1 \mathrm{mg} / \mathrm{mL}$ was prepared in methanol and diluted to $100 \mu \mathrm{g} / \mathrm{mL}$ in $50 \%$ methanol. The mobile phase comprised of $0.01 \mathrm{M}$ ammonium acetate : acetonitrile : methanol $(80: 10: 10, \mathrm{~V} / \mathrm{V} / \mathrm{V}(\%))$ at a flow rate of $1.2 \mathrm{~mL} / \mathrm{min}$.

Plasma concentrations of stavudine were determined according to the method described by Sarasa et al. [27] utilizing a validated high-performance liquid chromatographic (HPLC) separation [28]. Aliquots of $200 \mu \mathrm{L}$ of thawed patient plasma samples were added to the solid-phase cartridges and allowed to pass through the cartridge bed into clean dry glass tubes and then washed with two $1-\mathrm{mL}$ water aliquots. The cartridge bed was then dried by gentle suction. The stavudine was eluted from the solid-phase cartridge with $1 \mathrm{~mL}$ of methanol. The eluent was then evaporated to dryness under nitrogen stream. The residue was reconstituted with $65 \mu \mathrm{L}$ of the mobile phase, vortexed and $50 \mu \mathrm{L}$ of this sample was injected onto the HPLC system. Chromatograph curve peak heights were plotted against concentration to generate the standard curves.

The accuracy and interday precision of the method were estimated by assaying five replicate plasma samples at different concentrations, in three runs. The overall mean precision was defined by the coefficient of variation set at 
$2.5 \%$ from five standards of three different concentrations analyzed on the same day. Recovery of the study drug after the solid phase extraction was determined by comparing the observed stavudine concentrations in the extracted plasma, to those of nonprocessed standard solutions. Any possible interference from the endogenous compounds was investigated by the analysis of six different blank matrices. All reagents were of HPLC grade.

2.5. Statistical Methods. Plasma stavudine concentrations analyzed ranged from zero to $4254 \mathrm{nmol} / \mathrm{L}$. The steady state pharmacokinetic parameters of stavudine $30 \mathrm{mg}$ in HIV-infected adults ranges between $8 \pm 2 \mathrm{ng} / \mathrm{mL}(35.7 \pm$ $8.9 \mathrm{nmol} / \mathrm{L})$ and $536 \pm 454 \mathrm{ng} / \mathrm{mL}(2392.9 \pm 2026.8 \mathrm{nmol} / \mathrm{L})$ [29]. Patients with $95 \%$ and above self-reported adherence levels are expected to have a trough plasma drug concentration of not less than $36 \mathrm{nmol} / \mathrm{L}$. The $36 \mathrm{nmol} / \mathrm{L}$ is the documented cutoff for the lower boundary normal stavudine therapeutic concentrations [29]. A binary variable was created, indicating whether each patient's plasma drug concentrations were below $36 \mathrm{nmol} / \mathrm{L}$ or not, and this was the outcome of interest. In this analysis, the primary independent variable was the binary S-RA variable indicating whether the patient was $95 \%$ and above adherent to ART or not.

In comparative analyses, the Chi-square test was used to investigate the association between all categorical covariates and the outcome. For continuous variables which were normally distributed, the student $t$-test with equal variances was used to compare means within the outcome categories.

The primary aim of this analysis was to determine the association between stavudine plasma concentrations and SRA. This was achieved in classical Mantel Haenszel (MH) and logistic regression models. Crude associations between all categorical exposures and the outcome were determined in univariate logistic models, where statistical significance was assessed using the global likelihood ratio test. Confounding bias introduced in the crude association between plasma concentrations and S-RA from other patient-level covariates was assessed in multivariable logistic regression models. Here, the joint Wald test was used to assess statistical significance. Effects modification was also investigated in these models.

The secondary aim of this analysis was to validate S-RA against the actual-detected plasma drug concentrations. This was achieved by computing the sensitivity, specificity, and negative and positive predictive values.

All analyses were performed using Stata 11/IC (Stata Corp, College Station, TX, USA), all $P$ values were based on the $5 \%$ level of precision and all tests were two-tail based.

2.6. Ethical Considerations. All participants gave a written consent. The study protocol was approved by the Faculty of Medicine Research and Ethics Committee, Makerere University and the JCRC Institutional Review Board, while permission to conduct the study was granted by the Uganda National Council of Science and Technology.

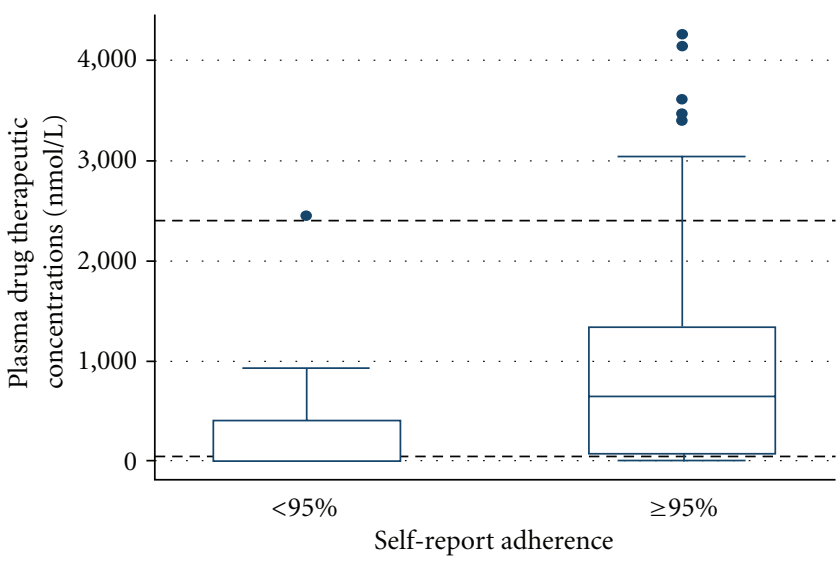

FIGURE 1: The broken horizontal lines indicate the 36 to $2400 \mathrm{nmol} / \mathrm{L}$ normal range levels of stavudine concentrations in steady state. The boxes indicate the lower quartile (Q1), the median (Q2), and upper quartile (Q3) limits of the concentrations, respectively. The upper and lower limits of the Whiskers indicate the minimum and maximum observations, whereas the dots above each upper cap of the whisker represent the concentrations considered to be outliers.

\section{Results}

All data from the 234 recruited patients were included in the final analysis. Alcohol consumption data was missing for four patients, CD4 measurements were missing for 65 patients, and body weight information was missing for nine patients. While fitting the models, records with missing data were automatically excluded.

Overall, 194/234 (82.9\%) patients reported S-RA of 95\% and above. The median plasma stavudine concentration for all patients was $517.9 \mathrm{nmol} / \mathrm{L}$ (range: $0,4253.8$, Interquartile Range: 0, 1183.0). Overall, 68/234 (29.1\%) patients had stavudine plasma concentrations less than $36 \mathrm{nmol} / \mathrm{L}$ (classified as below therapeutic range), whereas 166/234 (70.9\%) had stavudine plasma concentrations that were $36 \mathrm{nmol} / \mathrm{L}$ and above (classified as within or above therapeutic range). Figure 1 shows the distribution of plasma levels of stavudine among patients with S-RA below 95\%, compared to those with S-RA of $95 \%$ and above. The broken horizontal lines indicate the 36 to $2400 \mathrm{nmol} / \mathrm{L}$ normal range levels of stavudine concentrations in steady state. The boxes indicate the lower-quartile (Q1), the median- (Q2), and upper-quartile (Q3) limits of the concentrations respectively. The upper and lower limits of the Whiskers indicate the minimum and maximum observations, whereas the dots above each upper cap of the whisker represent the concentrations considered to be outliers.

Table 1 presents the distribution of S-RA, demographic and clinical characteristics by plasma drug concentration classification. Most 152/194 (78.4\%) patients with S-RA of 95\% and above were found to have within or above normal therapeutic concentrations of stavudine $(P<0.0001)$. However, $42 / 194(21.7 \%)$ of patients reporting good adherence actually had below normal drug concentrations. In unadjusted models, patients who reported $95 \%$ and above S-RA 
TABLE 1: The association between patients' demographic/clinical characteristics and plasma drug therapeutic concentration among patients on a stavudine-containing regimen in Uganda.

\begin{tabular}{|c|c|c|c|c|c|}
\hline & & \multicolumn{2}{|c|}{ Plasma drug concentration } & \multicolumn{2}{|c|}{ Crude association } \\
\hline & & Below normal range ${ }^{1}$ & Within or above normal range ${ }^{2}$ & Odds ratio $(95 \% \mathrm{CI})$ & $P$-value \\
\hline \multirow{2}{*}{$\begin{array}{l}\text { Self-report } \\
\text { Adherence }\end{array}$} & Below 95\% $(n=40)$ & $26(65.0 \%)$ & $14(35.0 \%)$ & [reference] & $<0.0001$ \\
\hline & $95 \%$ and above $(n=194)$ & $42(21.7 \%)$ & $152(78.4 \%)$ & $6.72(3.06,14.78)$ & \\
\hline \multirow{2}{*}{ Gender } & Male $(n=84)$ & $23(27.4 \%)$ & $61(72.6 \%)$ & [reference] & 0.6728 \\
\hline & Female $(n=150)$ & $45(30.0 \%)$ & $105(70.0 \%)$ & $0.88(0.49,1.59)$ & \\
\hline Age in years & Mean (SD) & $38.4(7.0)$ & $38.6(6.9)$ & $1.00(0.96,1.05)$ & 0.833 \\
\hline \multirow{2}{*}{ Employment status } & Not Employed $(n=96)$ & $23(24.0 \%)$ & $73(76.0 \%)$ & [reference] & 0.2079 \\
\hline & Employed $(n=133)$ & $42(31.6 \%)$ & $91(68.4 \%)$ & $0.68(0.38,1.24)$ & \\
\hline \multirow{2}{*}{ Marital Status } & Not married $(n=106)$ & $24(22.6 \%)$ & $82(77.4 \%)$ & [reference] & 0.0496 \\
\hline & Married $(n=128)$ & $44(34.4 \%)$ & $84(65.6 \%)$ & $0.56(0.31,1.01)$ & \\
\hline \multirow{2}{*}{ Education } & No Education $(n=16)$ & $5(31.3 \%)$ & $11(68.8 \%)$ & [reference] & 0.8419 \\
\hline & Some Education $(n=218)$ & $63(28.9 \%)$ & $155(71.1 \%)$ & $1.12(0.37,3.36)$ & \\
\hline \multirow{3}{*}{$\begin{array}{l}\text { Alcohol drinking } \\
\text { status }\end{array}$} & $\operatorname{Never}(n=144)$ & $42(29.2 \%)$ & $102(70.8 \%)$ & [reference] & 0.7946 \\
\hline & Stopped drinking $(n=26)$ & $8(30.8 \%)$ & $18(69.2 \%)$ & $0.93(0.37,2.29)$ & \\
\hline & Still drinking $(n=60)$ & $15(25.0 \%)$ & $45(75.0 \%)$ & $1.24(0.62,2.45)$ & \\
\hline $\begin{array}{l}\text { Current CD4 } \\
\text { count in cells/mL }\end{array}$ & Mean (SD) & $289(180)$ & $292(141)$ & $1.00(1.00,1.00)$ & 0.916 \\
\hline Body weight in kgs & Mean (SD) & $61.9(9.9)$ & $62.9(10.0)$ & $1.01(0.98,1.04)$ & 0.520 \\
\hline
\end{tabular}

${ }^{1}$ Stavudine plasma concentration below $36 \mathrm{nM} / \mathrm{mL}$

${ }^{2}$ Stavudine plasma concentration $36 \mathrm{nM} / \mathrm{mL}$ and above.

TABLE 2: Multivariate models explaining the association between plasma drug therapeutic concentrations and self-report adherence adjusted for demographic/clinical characteristics among patients on a stavudine-containing regimen in Uganda.

\begin{tabular}{|c|c|c|}
\hline \multirow[t]{2}{*}{ Adjusting variable } & \multicolumn{2}{|c|}{$\begin{array}{l}\text { Adjusted association between } \\
\text { plasma drug concentration } \\
\text { and self-reported adherence }\end{array}$} \\
\hline & $\begin{array}{c}\text { Adjusted odds ratio } \\
(95 \% \mathrm{CI})\end{array}$ & $P$-value \\
\hline None [crude association] & $6.72(3.06,14.78)$ & $<0.0001$ \\
\hline Gender & $7.13(3.18,16.01)$ & $<0.0001$ \\
\hline Age in years & $6.72(3.22,14.01)$ & $<0.0001$ \\
\hline Employment status & $6.54(2.92,14.65)$ & $<0.0001$ \\
\hline Marital status & $6.56(2.98,14.41)$ & $<0.0001$ \\
\hline Education & $6.75(3.06,14.87)$ & $<0.0001$ \\
\hline Alcohol drinking status & $6.94(3.10,15.52)$ & $<0.0001$ \\
\hline $\begin{array}{l}\text { Current CD4 count in } \\
\text { cells } / \mathrm{mL}\end{array}$ & $7.34(3.39,15.87)$ & $<0.0001$ \\
\hline Body weight in kgs & $8.49(3.21,22.46)$ & $<0.0001$ \\
\hline
\end{tabular}

were almost seven times more likely to have within or above therapeutic plasma stavudine concentrations, compared to those who reported less than 95\% S-RA (crude odds ratio: $6.72,95 \%$ confidence interval (CI): 3.06 to 14.78 ).

Table 2 presents results from multivariable models to determine the association between plasma stavudine concentration and S-RA, after adjusting for each demographic and clinical characteristic. We detected no evidence of effects modification from any of the independent study covariates. The final model was adjusted for gender and body weight, where patients who reported 95\% and above S-RA were almost eight times more likely (Adjusted Odds Ratio: 7.7, 95\% CI: 3.5 to $7.0, P<0.0001)$ to have within or above therapeutic plasma stavudine concentrations, compared to those who reported less than 95\% S-RA.

In this population, the sensitivity and specificity of SRA in determining actual adherence measured by the plasma concentration of stavudine within the therapeutic range was $91.6 \%$ and $38.2 \%$, respectively, while the respective positive and negative predictive values were computed as $78.4 \%$ and $65.0 \%$.

\section{Discussion}

The present study found that slightly over $80 \%$ of the patients reported to be adherent $(\mathrm{S}-\mathrm{RA} \leq 95 \%)$ to ART, a finding consistent with what has been reported elsewhere [15-17]. We also found out that patients with good S-RA were almost seven to eight times more likely to have therapeutic drug levels within or above therapeutic range. This positive association is critical for treatment success [1, 2, 30, 31]. However, $21.7 \%$ of patients reporting good adherence actually had insufficient plasma drug concentrations (false positives) (Table 1). These results reveal that, whereas high $\mathrm{S}$-RA rates to ART correlated well with normal therapeutic plasma drug levels among these patients, S-RA as a tool may have some limitations while identifying nonadherent patients. The specificity calculations implied that, for true 
nonadherent patients assessed for ART adherence, the SRA method is cable of identifying only 38 out of every one hundred nonadhering patients. The false positives subgroup of "good S-RA, but poor drug levels" would thus constitute thecategory of "intrinsic poor adherence". These may have higher risks of contributing to emergence of resistance to antiretroviral therapy. Furthermore, the pharmacokinetic characteristics of this group of patients need to be investigated, especially their variability of stavudine metabolism. It may be possible that these are fast metabolizers of stavudine, hence presenting with low plasma concentrations.

Out of the 40 S-RA nonadherent participants in this study, $14(35.0 \%)$ had plasma stavudine concentrations within or above normalrange (Table 1). This may be attributed to the fact that, prior to sample collection, patients may have taken their dose for that morning, even though they might have been classified as nonadherent according to the three-month S-RA calculations. Alternatively, this finding may be attributed to pharmacokinetic factors, including the fact that these patients may be slow ART metabolizers, which is linked to genetic variability $[32,33]$. These false negatives do present an opportunity for further scientific investigations.

Generally, nonadherence to ART has been viewed as a significant public health concern based on the perception that nonadherence would speed the development and transmission of drug-resistant strains to the masses [2, $3,11]$. However, while focus of interventions to address nonadherence is aimed at populations thought to have lowest adherence rates, these are sometimes not the populations in which actual resistance occurs [34]. The existence of virologic failures among adhering patients may need further scientific investigations [35]. Our recommendation would be to encourage patient care providers, main stake holder ministries, and legislators in Sub-Saharan Africa into considering occasional drug bioavailability monitoring to ensure success of ART programs in the region.

Recently, there has been increasing recognition of proper and adequate adherence assessment as a crucial factor in improving treatment outcomes [11]. In this investigation, we recognize that improving adherence and subsequently treatment outcomes will require a combination of methods appropriate to the patient and clinical settings $[22,36]$. Timely interventions should include dedicated educational and collaborative efforts offered to every patient, and adherence monitoring in the home setting by community outreach programs. In this way, the true nonadherent patients will quickly be identified for timely intervention to improve their adherence rates even where drug level analysis is not possible such as in resource-limited countries like Uganda.

\section{Conclusions}

Patients who report high S-RA are most likely to adhere to therapy, but some of them were probably nonadherent basing on the suboptimal plasma drug levels, indicating that S-RA lacks sufficient specificity for detecting nonadherence. We thus recommend that, whenever possible drug level determination should be performed since use of S-RA may result in failure to identify the non adherent patients which could have potential implications for drug resistance. Since some patients in this study showed very high levels of the drug in plasma, drug level determination would be necessary in patients who show signs of adverse effect to ART before switching medication.

\section{Limitations of the Study}

The cross-sectional study design provided no opportunity for a complete measurement of all CD4 cell counts and to monitor all patients' body weight gain, as measures of clinical response to therapy.

\section{Authors' Contribution}

R. Balikuddembe, C. Obua and P. Waako conceptualized and designed the study, and participated in the interpretation of the data. R. Balikuddembe, D. Musoke, M. Ntale and S. Baveewo conducted the study and performed the drug level analysis. J. Kayiwa and C. Obua performed the statistical analysis and drafted the manuscript.All authors read and approved the final manuscript.

\section{Conflict of Interests}

All authors declare no conflict of interests regarding the findings presented in this paper.

\section{Acknowledgments}

The study was conducted using seed funds from the World Health Organization, Country Office (Uganda) and additional funds from the Department of Pharmacology and Therapeutics, Makerere University. We would like to acknowledge contribution of the Joint Clinical Research Centre staff and all the participants who made it possible to carry out this study.

\section{References}

[1] A. Ammassari, M. P. Trotta, R. Murri et al., "Correlates and predictors of adherence to highly active antiretroviral therapy: overview of published literature," Journal of Acquired Immune Deficiency Syndromes, vol. 31, no. 3, pp. S123-S127, 2002.

[2] J. M. Raboud, M. Harris, S. Rae, and J. S. G. Montaner, "Impact of adherence on duration of virological suppression among patients receiving combination antiretroviral therapy," HIV Medicine, vol. 3, no. 2, pp. 118-124, 2002.

[3] A. M. Abaasa, J. Todd, K. Ekoru et al., "Good adherence to HAART and improved survival in a community HIV/AIDS treatment and care programme: the experience of the AIDS Support Organization (TASO), Kampala, Uganda," BMC Health Services Research, vol. 8, article no. 241, 2008.

[4] F. Bajunirwe, E. J. Arts, D. J. Tisch, C. H. King, S. M. Debanne, and A. K. Sethi, "Adherence and treatment response among HIV-1-infected adults receiving antiretroviral therapy in a rural government hospital in Southwestern Uganda," Journal 
of the International Association of Physicians in AIDS Care, vol. 8, no. 2, pp. 139-147, 2009.

[5] F. Bajunirwe, D. J. Tisch, C. H. King, E. J. Arts, S. M. Debanne, and A. K. Sethi, "Quality of life and social support among patients receiving antiretroviral therapy in Western Uganda," AIDS Care, vol. 21, no. 3, pp. 271-279, 2009.

[6] H. Bussmann, C. W. Wester, A. Thomas et al., "Response to zidovudine/didanosine-containing combination antiretroviral therapy among hiv-1 subtype c-infected adults in botswana: two-year outcomes from a randomized clinical trial," Journal of Acquired Immune Deficiency Syndromes, vol. 51, no. 1, pp. 37-46, 2009.

[7] J. Byakika-Tusiime, J. Crane, J. H. Oyugi et al., "Longitudinal antiretroviral adherence in HIV+ Ugandan parents and their children initiating HAART in the MTCT-plus family treatment model: role of depression in declining adherence over time," AIDS and Behavior, vol. 13, no. 1, pp. S82-S91, 2009.

[8] L. W. Chang, S. Alamo, S. Guma et al., "Two-year virologic outcomes of an alternative AIDS care model: evaluation of a peer health worker and nurse-staffed community-based program in uganda," Journal of Acquired Immune Deficiency Syndromes, vol. 50, no. 3, pp. 276-282, 2009.

[9] B. H. Chi, R. A. Cantrell, I. Zulu et al., "Adherence to first-line antiretroviral therapy affects non-virologic outcomes among patients on treatment for more than 12 months in Lusaka, Zambia," International Journal of Epidemiology, vol. 38, no. 3, pp. 746-756, 2009.

[10] R. Elema, C. Mills, O. Yun et al., "Outcomes of a remote, decentralized health center-based HIV/AIDS antiretroviral program in Zambia, 2003 to 2007," Journal of the International Association of Physicians in AIDS Care, vol. 8, no. 1, pp. 60-67, 2009.

[11] D. C. Khakha, "Adherence is key to HIV treatment," The Nursing Journal of India, vol. 99, no. 6, pp. 125-127, 2008.

[12] D. Meya, L. A. Spacek, H. Tibenderana et al., "Development and evaluation of a clinical algorithm to monitor patients on antiretrovirals in resource-limited settings using adherence, clinical and CD4 cell count criteria," Journal of the International AIDS Society, vol. 12, article 3, 2009.

[13] A. D. Müller, L. Myer, and H. Jaspan, "Virological suppression achieved with suboptimal adherence levels among South African children receiving boosted protease inhibitor-based antiretroviral therapy," Clinical Infectious Diseases, vol. 48, no. 1, pp. e3-e5, 2009.

[14] S. C. J. M. Vervoort, M. H. F. Grypdonck, A. De Grauwe, A. I. M. Hoepelman, and J. C. C. Borleffs, "Adherence to HAART: processes explaining adherence behavior in acceptors and non-acceptors," AIDS Care, vol. 21, no. 4, pp. 431-438, 2009.

[15] D. R. Bangsberg, F. M. Hecht, H. Clague et al., "Provider assessment of adherence to HIV antiretroviral therapy," Journal of Acquired Immune Deficiency Syndromes, vol. 26, no. 5, pp. 435-442, 2001.

[16] J. Byakika-Tusiime, J. H. Oyugi, W. A. Tumwikirize, E. T. Katabira, P. N. Mugyenyi, and D. R. Bangsberg, "Adherence to HIV antiretroviral therapy in HIV+ Ugandan patients purchasing therapy," International Journal of STD and AIDS, vol. 16, no. 1, pp. 38-41, 2005.

[17] S. K. Muyingo, A. S. Walker, A. Reid et al., "Patterns of individual and population-level adherence to antiretroviral therapy and risk factors for poor adherence in the first year of the DART trial in Uganda and Zimbabwe," Journal of Acquired Immune Deficiency Syndromes, vol. 48, no. 4, pp. 468-475, 2008.
[18] J. Farley, S. Hines, A. Musk, S. Ferrus, and V. Tepper, "Assessment of adherence to antiviral therapy in HIV-infected children using the medication event monitoring system, pharmacy refill, provider assessment, caregiver self-report, and appointment keeping," Journal of Acquired Immune Deficiency Syndromes, vol. 33, no. 2, pp. 211-218, 2003.

[19] O. M. Minzi and A. S. Naazneen, "Validation of self-report and hospital pill count using unannounced home pill count as methods for determination of adherence to antiretroviral therapy," Tanzania Journal of Health Research, vol. 10, no. 2, pp. 84-88, 2008.

[20] J. H. Wagner, A. C. Justice, M. Chesney, G. Sinclair, S. Weissman, and M. Rodriguez-Barradas, "Patient- and providerreported adherencetoward a clinically useful approach to measuring antiretroviral adherence," Journal of Clinical Epidemiology, vol. 54, no. 12, pp. S91-S98, 2001.

[21] C. A. Bova, K. P. Fennie, G. J. Knafl, K. D. Dieckhaus, E. Watrous, and A. B. Williams, "Use of electronic monitoring devices to measure antiretroviral adherence: practical considerations," AIDS and Behavior, vol. 9, no. 1, pp. 103-110, 2005.

[22] F. M. Hecht, "Measuring HIV treatment adherence in clinical practice," AIDS clinical care, vol. 10, no. 8, pp. 57-59, 1998.

[23] J. F. Steiner and A. V. Prochazka, "The assessment of refill compliance using pharmacy records: methods, validity, and applications," Journal of Clinical Epidemiology, vol. 50, no. 1, pp. 105-116, 1997.

[24] J. M. Simoni, A. E. Kurth, C. R. Pearson, D. W. Pantalone, J. O. Merrill, and P. A. Frick, "Self-report measures of antiretroviral therapy adherence: a review with recommendations for HIV research and clinical management," AIDS and Behavior, vol. 10, no. 3, pp. 227-245, 2006.

[25] R. L. Schaeffer, W. Mendenhall, and L. Ott, Elementary Survey Sampling, Duxbury Press, Belmont, Calif, USA, 4th edition, 1990.

[26] L. Kish, Survey Sampling, John Wiley and Sons, New York, NY, USA, 1965.

[27] M. Sarasa, N. Riba, L. Zamora, and X. Carné, "Determination of stavudine in human plasma and urine by high-performance liquid chromatography using a reduced sample volume," Journal of Chromatography B, vol. 746, no. 2, pp. 183-189, 2000.

[28] J. L. Wiesner, F. C. W. Sutherland, M. J. Smit et al., "Sensitive and rapid liquid chromatography-tandem mass spectrometry method for the determination of stavudine in human plasma," Journal of Chromatography B, vol. 773, no. 2, pp. 129-134, 2002.

[29] F. Becher, R. Landman, S. Mboup et al., "Monitoring of didanosine and stavudine intracellular trisphosphorylated anabolite concentrations in HIV-infected patients," AIDS, vol. 18, no. 2, pp. 181-187, 2004.

[30] D. R. Bangsberg, E. P. Acosta, R. Gupta et al., "Adherenceresistance relationships for protease and non-nucleoside reverse transcriptase inhibitors explained by virological fitness," AIDS, vol. 20, no. 2, pp. 223-231, 2006.

[31] R. H. Haubrich, S. J. Little, J. S. Currier et al., "The value of patient-reported adherence to antiretroviral therapy in predicting virologic and immunologic response," AIDS, vol. 13, no. 9, pp. 1099-1107, 1999.

[32] A. M. Martin, D. Nolan, S. Gaudieri, E. Phillips, and S. Mallal, "Pharmacogenetics of antiretroviral therapy: genetic variation of response and toxicity," Pharmacogenomics, vol. 5, no. 6, pp. 643-655, 2004.

[33] V. Tozzi, "Pharmacogenetics of antiretrovirals," Antiviral Research, vol. 85, no. 1, pp. 190-200, 2010. 
[34] D. R. Bangsberg, A. R. Moss, and S. G. Deeks, "Paradoxes of adherence and drug resistance to HIV antiretroviral therapy," Journal of Antimicrobial Chemotherapy, vol. 53, no. 5, pp. 696699, 2004.

[35] P. T. Nieuwkerk and F. J. Oort, "Self-reported adherence to antiretroviral therapy for HIV-1 infection and virologic treatment response: a meta-analysis," Journal of Acquired Immune Deficiency Syndromes, vol. 38, no. 4, pp. 445-448, 2005.

[36] J. C. Chalker, T. Andualem, L. N. Gitau et al., "Measuring adherence to antiretroviral treatment in resource-poor settings: the feasibility of collecting routine data for key indicators," BMC Health Services Research, vol. 10, article no. 43, 2010. 

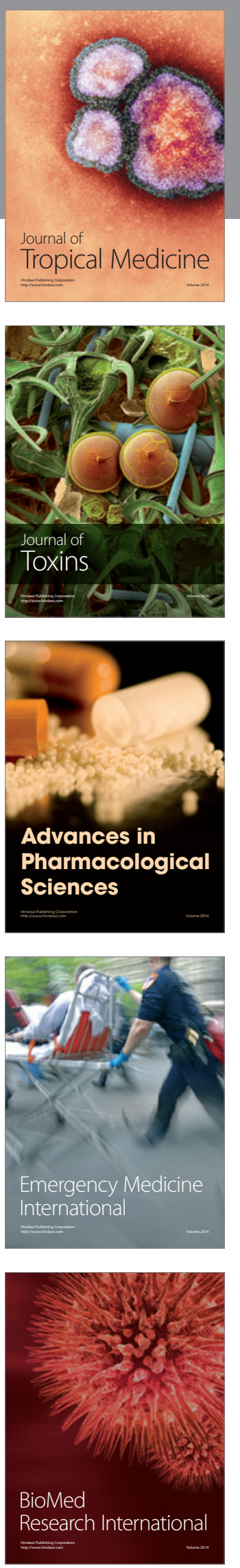
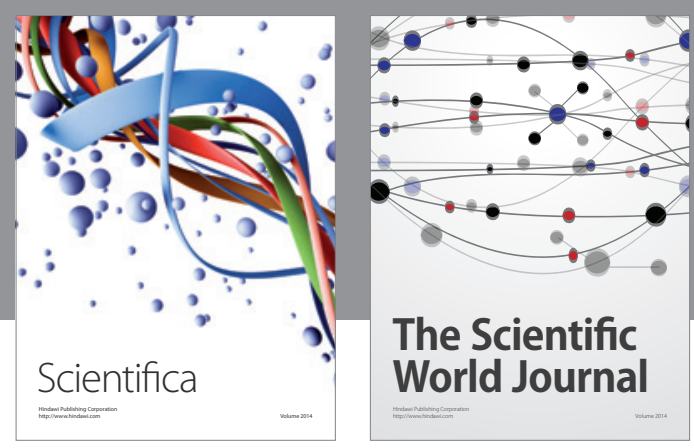

The Scientific World Journal
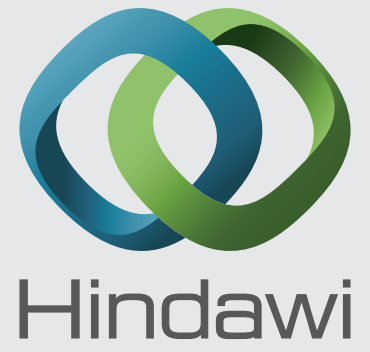

Submit your manuscripts at

http://www.hindawi.com
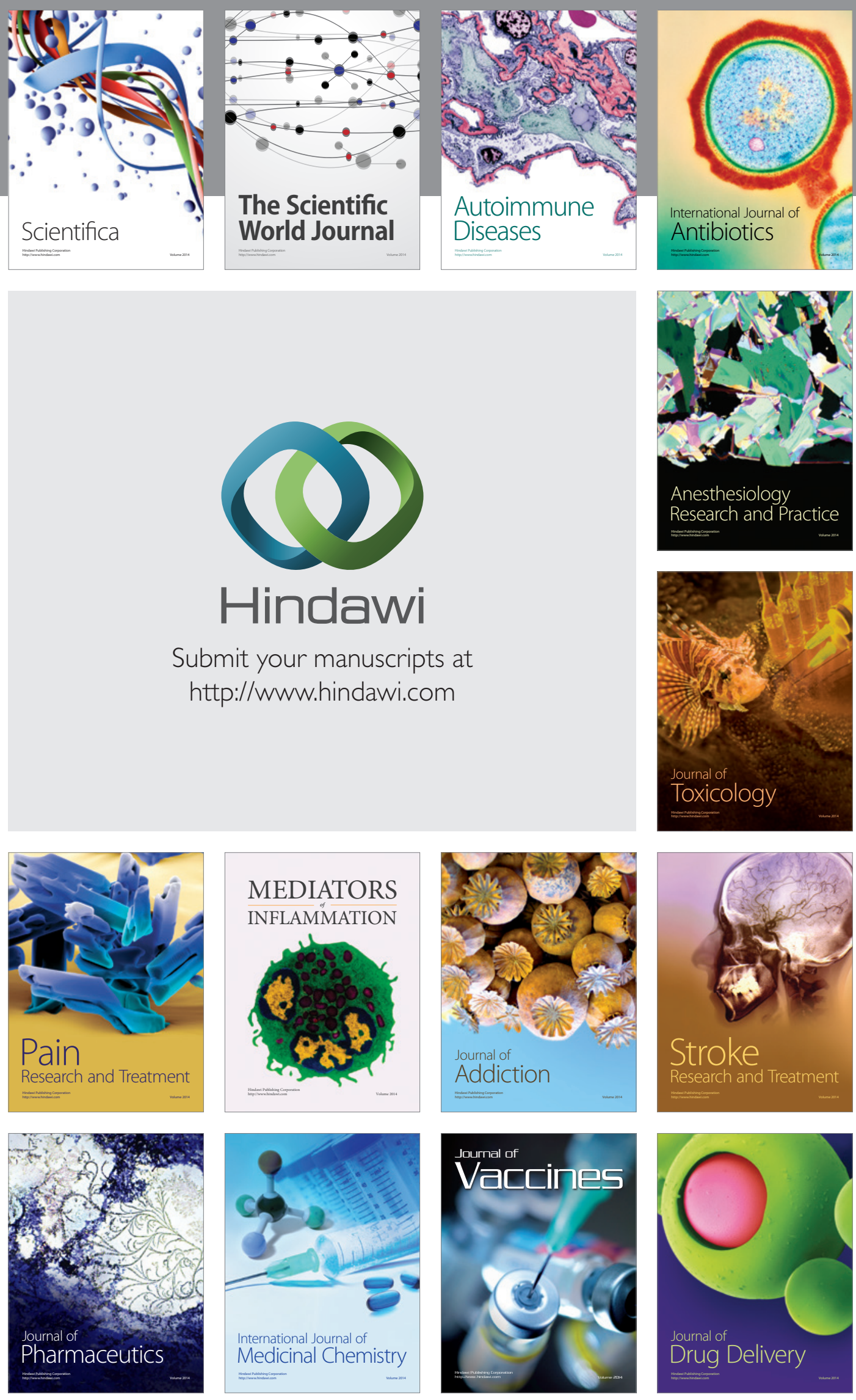